\title{
As políticas curriculares da educação profissional e o trabalho docente
}

\author{
Néri Emílio Soares Júnior ${ }^{1}$ \\ ORCID: 0000-0001-7841-2097 \\ Lívia Freitas Fonseca Borges² \\ ORCID 0000-0002-4956-0522
}

\section{Resumo}

Este artigo analisa o processo de implantação das atuais Diretrizes Curriculares Nacionais para a Educação Profissional Técnica de Nivel Médio (Parecer CNE/CEB n. 11/2012 e Resolução CNE/CEB n. 06/2012) em uma instituição de educação profissional no estado de Goiás. Para tanto, foi realizada uma pesquisa do tipo estudo de caso, que teve como procedimentos de levantamento de dados a análise documental, a observação, a entrevista semiestruturada e a instrução ao sósia. Os documentos analisados foram referentes às políticas curriculares e aos níveis de decisão curricular no âmbito da instituição escolar e os sujeitos da pesquisa foram gestores e professores. A implantação das diretrizes curriculares vem sendo feita a partir de ações da Reitoria, tais como: alteração dos projetos pedagógicos e das matrizes curriculares dos cursos técnicos; realização de um programa de formação continuada de docentes e técnicos-administrativos; organização e desenvolvimento de eventos de caráter científico; realização de um trabalho piloto de reformulação curricular e diálogos entre representantes da gestão e professores dos diferentes campi. Entretanto, essas ações têm apresentado pouco efeito nas práticas dos professores, uma vez que, no desenvolvimento do seu trabalho, são influenciados por fatores como a dimensão pessoal e o caráter socioeconômico do trabalho, a organização do trabalho pedagógico, os estudantes, o campo disciplinar e a área de atuação, a experiência profissional e os valores dos próprios professores, entre outros.

\section{Palavras-chave}

Políticas curriculares - Educação profissional - Trabalho docente.

1- Instituto Federal de Ciência, Educação e Tecnologia de Goiás (IFG), Goiânia, Goiás, Brasil. Contato: neriesjr@gmail.com

2- Faculdade de Educação da Universidade de Brasília, Brasília, Distrito Federal, Brasil. Contato: liviaffb@terra.com.br 


\section{Curriculum policies for vocational education and teaching work}

\section{Abstract}

This article investigates the process of implementation of the current National Curricular Guidelines for Technical and Vocational Education of High School Level (Statement NCE/ CBE n. 11/2012 and Resolution NCE/CBE n. 06/2012) in a vocational education institution in the state of Goiás. For this, a case study was carried out, which data survey procedures were documental analysis, observation, semi-structured interview, and instruction to the double. The documents analyzed were related to the curricular policies and the levels of the curricular decision in the school institution. The managers and teachers participated as investigation subjects. The implementation of the curricular guidelines has been made from actions of the Dean, such as remodeling of pedagogical projects and curricular matrices of technical courses; building a program of continuing education for teachers and administrative staff; organizing and developing scientific events; conducting a pilot work of curricular reformulation and dialogues between management representatives and teachers of different campuses. However, these actions have had little effect on teachers' practices. Since the development of their work, they are influenced by factors such as personal and socioeconomic dimension of the work, pedagogical work organization, students, disciplinary field, action area, teachers'values, and professional experience, among others.

\section{Keywords}

Curricular policies - Vocational education - Teaching work.

\section{Apresentação}

0 Brasil, nas últimas décadas, vem passando por um amplo e profundo processo de reforma na política educacional brasileira, com o objetivo de estabelecer novos rumos para a educação. Nesse processo, duas características chamam a atenção: o lugar estratégico do currículo como indutor de mudanças do ensino nos diferentes níveis e modalidades de ensino e da realidade escolar (CANDAU, 2001) e a descontinuidade dos projetos políticos educacionais colocados em prática (SAVIANI, 2008). A educação profissional é uma modalidade de ensino que tem sofrido os desdobramentos desse momento da política educacional brasileira. Sendo assim, desde os anos de 1990, diferentes projetos políticopedagógicos estão em disputa pela reforma dessa modalidade de ensino.

Com a aprovação da Lei de Diretrizes e Bases da Educação Nacional (LDB), Lei n. 9394/96 (BRASIL, 1996), a educação profissional foi concebida como a possibilidade de integração com as diferentes formas da educação, o trabalho, a ciência e a tecnologia e 
como a possibilidade da integração entre educação profissional e educação geral. É, pois, uma perspectiva que procura superar a conhecida dualidade da formação para o trabalho versus a formação para a vida, que é uma importante marca da educação brasileira. Essa proposta foi resultado da ação de professores, intelectuais, entidades científicas, entre outros (SAVIANI, 1999).

No ano seguinte à aprovação da LDB, foi aprovado um conjunto de ações, como a promulgação do Decreto n. 2.208, em 17 de abril de 1997 (BRASIL, 1997), que estabeleceu, entre outras medidas, a separação entre a educação profissional técnica do ensino médio e o currículo por competências, contrariando, dessa forma, a proposta da integração do ensino profissional com o ensino médio, indicada na LDB. Essas mudanças foram relacionadas com as influências dos organismos internacionais e embaladas por questões econômicas e mercadológicas (FRIGOTTO; CIAVATTA; RAMOS, 2012; FERRETTI, 1997; KUENZER, 2008).

Em 1999, foram definidas as Diretrizes Curriculares Nacionais para a Educação Profissional Técnica de Nivel Médio (DCNEP), conforme Parecer CNE/CEB n. 16/99 e Resolução CNE/CEB n. 4/99 (BRASIL, 1999), com a concepção de educação profissional alinhada ao Decreto n. 2.208/97. Assim, a separação entre a referida modalidade educacional com o ensino médio foi mantida. Além da organização dessa modalidade por áreas profissionais, o currículo permaneceu sob o fundamento das competências profissionais (BRASIL, 1999).

Com o governo Lula da Silva, no ano de 2004, foi aprovado o Decreto n. 5.154/04 (BRASIL, 2004), resultado da mobilização e debate de pesquisadores e professores que tiveram como pano de fundo a discussão sobre a educação politécnica e, consequentemente, o objetivo de superar a dualidade estrutural entre formação geral e formação técnica ${ }^{3}$. Assim, no referido decreto, foram instituídas a possibilidade de integração entre educação profissional técnica de nível médio com o ensino médio, a organização dos cursos por áreas profissionais e a articulação da educação, trabalho, ciência e tecnologia. Dessa forma, o Decreto n. 5.154/04 apresentou significativos avanços da proposta de educação profissional técnica para o nível médio (FRIGOTT0; CIAVATTA; RAMOS, 2012). Em 2012, durante o governo Dilma Rousseff, foram aprovadas as novas DCNEP (Parecer CNE/CEB n. 11/12 e Resolução CNE/CEB n. 06/12), nas quais se procurou estabelecer articulações com o Decreto n. 5154/04.

Observa-se então que, no âmbito da educação profissional, existe um intenso movimento de alterações das políticas da educação profissional para o nível médio, principalmente quando ocorrem mudanças de projetos de governo.

A descontinuidade das políticas curriculares da educação profissional, mediante transições e rupturas em diferentes projetos para esta modalidade de ensino, interfere na prática pedagógica dos professores, pois esse movimento provoca insegurança no trabalho

\footnotetext{
3 - Dualidade estrutural é compreendido pela "divisão" da escola em duas, uma com caráter propedêutico e outra com caráter profissional. A escola com caráter propedêutico tem o objetivo de promover a formação humanística, de cultura geral, voltado para os dirigentes e intelectuais. A escola de caráter profissional, por sua vez, objetiva promover a educação exclusivamente técnico-profissional, voltada para os trabalhadores. A dualidade estrutural se fundamenta na divisão social do trabalho, em que homens são encaminhados para funções intelectuais e manuais de acordo com sua classe social (KUENZER, 1994). Autores como Frigotto; Ciavatta e Ramos (2012) e Kuenzer (1994), por exemplo, entendem que, principalmente, até os anos de 1990, a dualidade estrutural se configura como uma forte expressão das políticas educacionais brasileiras voltadas para o Ensino Médio.
} 
docente, contribuindo para que o proposto, no âmbito das políticas curriculares, não se efetive na prática (SILVA; MARQUES, 2007). Também se pode inferir que, pela velocidade como as mudanças estão sendo realizadas, não há tempo para assimilação das políticas por parte dos professores.

Diante do quadro apresentado, torna-se importante analisar como as instituições de educação profissional estão colocando em curso as políticas curriculares para a educação profissional técnica de nível médio. Dessa forma, o objetivo da pesquisa foi analisar o processo de implantação das DCNEP em uma escola de formação profissional. Os objetivos específicos foram: a) examinar a proposta curricular para os cursos de educação profissional de nível médio contida nas DCNEP e nos projetos pedagógicos da Instituição Formadora para analisar o processo de recontextualização dessas diretrizes curriculares; b) investigar como foi encaminhada a reformulação curricular na Instituição Formadora nos diferentes níveis de decisão curricular e o seu impacto na organização e desenvolvimento do trabalho docente no contexto geral da escola e no contexto da aula; c) analisar como os professores trabalham ao colocarem o currículo em ação, procurando identificar os fatores que influenciam esse trabalho; e d) investigar como gestores e professores avaliam o processo de reformulação curricular.

A pesquisa foi desenvolvida a partir de três grandes categorias, que são educação profissional, políticas curriculares e trabalho docente, tendo por base a articulação de dois eixos teóricos: a) políticas curriculares da educação profissional e b) trabalho docente.

0 delineamento da investigação foi realizado a partir da noção de desenvolvimento curricular de Gimeno Sacristán (1998, 2000, 2013a, 2013b). 0 autor propõe uma concepção processual de currículo, uma perspectiva que procura articular o projeto curricular expresso desde as políticas públicas até o contexto da prática pedagógica dos professores, com o currículo materializado em diferentes níveis. Nesse processo, os professores são os principais agentes do currículo, visto que recontextualizam as propostas curriculares que chegam às suas mãos (BERNSTEIN, 1996).

0 primeiro nível do desenvolvimento curricular é o das políticas curriculares, que estabelece um projeto de educação advindo das políticas públicas educacionais, sendo denominado currículo prescrito ou oficial (GIMENO SACRISTÁN, 1998). Por vezes, o currículo oficial passa a ser interpretado e consubstanciado em propostas de conteúdos disciplinares, em formato de livros e outros materiais pedagógicos que são utilizados pelos professores (GIMENO SACRISTÁN, 1998, 2000, 2013a, 2013b), denominado de currículo apresentado aos professores.

0 currículo prescrito, ao chegar às instituições de ensino, sofre interferência do professor e dos demais sujeitos que o vivenciam. Nesse processo, Gimeno Sacristán (2000) considera o professor como principal mediador entre o currículo e os estudantes, um agente ativo no processo de desenvolvimento curricular. Sob a perspectiva coletiva do professorado, o projeto educacional que chega das orientações curriculares oficiais é interpretado e depois é que se elabora o projeto pedagógico institucional.

0 próximo nível do desenvolvimento curricular refere-se ao currículo em ação, que se configura como a prática realizada pelos professores em situação concreta de seu trabalho (GIMENO SACRISTÁN, 2013a). 0 resultado do currículo em ação é denominado de 
currículo realizado, que são os efeitos diversos de ordem cognitiva, afetiva, social, moral, nos sujeitos que participam do desenvolvimento curricular. Por fim, tem-se o currículo expresso em resultados escolares comprováveis que são refletidos no rendimento escolar, denominado de currículo avaliado.

Com o objetivo de contribuir para a compreensão das relações que ocorrem nas diferentes instâncias ou níveis do currículo, foi utilizada a noção de recontextualização, desenvolvida pelo autor inglês Basil Bernstein. Essa noção foi formulada no contexto da teoria do dispositivo pedagógico (MAINARDES; STREMEL, 2010) visando a analisar o processo de transformação de uma disciplina ou um campo do conhecimento para se constituir conhecimento escolar. A recontextualização constitui-se uma transferência de textos de um contexto para outro, como, por exemplo, do contexto acadêmico para o contexto de um sistema educacional ligado à esfera federal, estadual ou municipal; do contexto de uma rede de ensino para o de uma escola.

Para realizar a análise do currículo em ação, foi tomado como referência o trabalho docente, cujo objetivo foi compreender os fatores que influenciam esse trabalho. A análise do trabalho teve como fundamento teórico o ponto de vista da atividade, a partir das contribuições da ergologia (SCHWARTZ, 1996, 2002, 2003, 2004, 2006, 2010, 2011; SCHWARTZ; DUC; DURRIVE, 2007). De forma sintética, a ergologia propõe uma abordagem pluridisciplinar com o objetivo de "[...] melhor conhecer e, sobretudo, de melhor intervir sobre as situações de trabalhar para transformá-las” (SCHWARTZ, 2007, p. 36). 0 trabalho é considerado como um lugar de acontecimentos complexos (SCHWARTZ, 2004), no qual se desenvolve o fazer industrioso humano (SCHWARTZ, 2006).

A partir da abordagem ergológica, o sujeito, em sua ação no trabalho, deve cumprir uma série de tarefas estabelecidas por normas que lhe são prescritas. No entanto, o sujeito não se limita a acatar as prescrições, uma vez que ele, de forma constante, as reinventa, renormaliza. Assim, nesse processo, sempre existe a combinação entre normas que são antecedentes, que são mais ou menos visíveis, acumuladas, passíveis de ensino, prescritíveis, codificáveis com as renormalizações, mais ou menos ressingularizantes (SCHWARTZ, 2011).

Um importante aspecto a se considerar é que as normas são inacabadas, pois o meio sempre é imprevisivel ou infiel: "[...] o meio é sempre mais ou menos infiel, ele jamais se repete exatamente de um dia para outro ou de uma situação para outra" (SCHWARTZ, 2007, p. 191). Assim, os trabalhadores desenvolvem estratégias que são singulares para responder aos desafios apresentados pelo meio.

Quanto à organização, este texto apresenta-se da seguinte forma: no primeiro momento, são descritos os procedimentos da pesquisa; e no segundo, de forma sucinta, o aporte teórico utilizado e, por fim, os achados da pesquisa.

\section{Os procedimentos de pesquisa}

Esta pesquisa foi um estudo de caso realizado em um campus de instituição de educação profissional no estado de Goiás, que é parte da Rede Federal de Educação Profissional, Científica e Tecnológica. Então, para resguardar a identidade dos envolvidos 
foram usados nomes genéricos Campus Formador e Instituição Formadora para se referir, respectivamente, ao campus e à instituição onde foi desenvolvida a pesquisa.

A Instituição Formadora tem uma estrutura multicampi, com 13 polos, em 12 cidades do estado de Goiás. Oferece cursos de formação profissional na educação básica e no ensino superior, tais como cursos técnicos de nível médio nas modalidades integradas ao ensino médio e à educação de jovens e adultos, subsequentes e concomitantes ao ensino médio, cursos de tecnologia, bacharelado e licenciatura, no nível de graduação, além de cursos de pós-graduação lato sensu e stricto sensu. Nessa instituição, também são ofertados cursos de extensão e de formação profissional de curta duração.

0 Campus Formador está localizado em uma cidade que é parte da região metropolitana de Goiânia. Atualmente, oferta cursos técnicos, cursos de graduação e um curso de pós-graduação lato sensu, sendo que os cursos técnicos são: Automação Industrial, Edificações, Eletrotécnica, Informática para Internet e Segurança para o Trabalho; os cursos de graduação são: Engenharia Civil e Engenharia Elétrica; e o curso de pós-graduação é a Especialização em Ensino de Humanidades.

0 trabalho de campo teve início em agosto de 2017 e término em março de 2018. Os procedimentos de levantamento de evidências foram a análise documental, a entrevista semiestruturada, o método de instrução ao sósia e a observação. Os interlocutores da pesquisa foram cinco gestores e sete docentes. Os gestores entrevistados foram o PróReitor de Ensino, a Diretora de Desenvolvimento de Ensino e o Coordenador Geral de Ensino Médio, que fazem parte da equipe da Pró-Reitoria de Ensino (Proen), o Diretor Geral e o Gerente de Ensino do Campus Formador, que fazem parte da equipe gestora do Campus Formador. Os docentes participantes foram dois professores da área profissional (Informática e Edificações) e os demais da área de formação geral (Educação Física, Química, Biologia, Matemática e Sociologia). Os documentos analisados foram referentes aos diferentes níveis de desenvolvimento curricular e ao trabalho prescrito, a saber: as atuais DCNEP e demais documentos oriundos das políticas curriculares, o Projeto de Desenvolvimento Institucional (PDI), os Projetos Pedagógicos dos Cursos (PPC) técnicos, os planos de curso de professores e documentos referentes ao regulamento das atividades docentes da Instituição Formadora.

Foi realizada entrevista semiestruturada com os gestores e os professores, procurando identificar como esses sujeitos avaliam e se relacionam com o processo de reformulação curricular, e ainda para levantar evidências sobre o trabalho docente.

0 método de instrução ao sósia foi realizado com dois professores com grupo composto por três docentes da Instituição Formadora. 0 processo aconteceu em três momentos: a) no primeiro, os sujeitos participantes foram confrontados pela mediação da atividade regulada ao sósia; b) no segundo momento, houve a transcrição feita pelos participantes; e c) no terceiro momento, foi realizado o comentário escrito sobre a forma e o conteúdo da transcrição. 0 objetivo foi buscar o confronto em dois tempos: no primeiro, do sujeito com si mesmo pela mediação da atividade da regra do sósia; e, no segundo, a partir de materializações desse intercâmbio pela mediação de uma atividade de escritura. A duração do procedimento foi de, aproximadamente, 40 minutos em cada intervenção 
e foi realizado em uma sala restrita. Ele permitiu avançar as situações reais do trabalho e identificar as formas singulares como os professores trabalham.

As observações foram de forma aberta e sistemática (GUÉRIN et al., 2001). Sendo assim, nas primeiras visitas, foram observações abertas da própria instituição, principalmente da disposição e organização do espaço físico, dos meios de trabalho dos professores nos diferentes espaços da escola, durante intervalos das aulas na interação com colegas, técnicos-administrativos e estudantes. 0 objetivo dessas observações foi levantar evidências que contribuíssem para a análise de situações relacionadas ao funcionamento geral da escola. Quanto às observações sistemáticas, essas foram realizadas no trabalho docente, em atividades de planejamento coletivo e no ensino, no contexto da aula de dois professores, um que ministra disciplina relacionada com a área profissional (Informática) e outra professora que ministra disciplina de formação geral (Biologia). Esses docentes serão denominados de professor Celso e professora Bertha, respectivamente. Em relação ao professor Celso, foram observadas duas aulas das disciplinas Lógica de Programação do $1^{\circ}$ ano e Desenvolvimento de Aplicativos Móveis Avançados (DAMA) do $3^{\circ}$ ano do curso de Informática para Internet e da professora Bertha foram observadas duas aulas de Biologia no $1^{\circ}$ e no $2^{\circ}$ ano do curso de Eletrotécnica.

A análise das evidências foi feita a partir de dois momentos: a) organização dos dados, com transcrição e categorização das diferentes fontes de evidência; e b) confronto das diferentes fontes de evidência com a literatura.

\section{As políticas curriculares de Educação Profissional}

A respeito das políticas curriculares da Educação Profissional Técnica de Nível Médio, foram analisadas as DCNEP (Parecer CNE/CEB n. 11/12 e Resolução CNE/CEB n. 06/12) (BRASIL, 2012a, 2012b), que são as referências para as instituições na elaboração dos seus currículos.

De um modo geral, as DCNEP constituem-se como documentos que apresentam uma proposta de formação humana e profissional considerada dual. Isso porque o seu projeto apresenta elementos que possibilitam pensar propostas de formação de trabalhadores em duas perspectivas distintas: o primeiro projeto, que se aproxima de uma concepção ampliada de formação humana, possibilita pensar na superação da dualidade histórica existente entre a formação técnica e a formação geral do trabalhador; e o segundo projeto, que se aproxima de projeto de formação unilateral do homem, é voltado para os interesses capitalistas.

A respeito da primeira perspectiva de formação, as DCNEP apresentam as seguintes proposições: a) a articulação entre educação profissional e a formação geral, estabelecida por meio da oferta de cursos integrados de educação profissional e o ensino médio e a integração entre saberes específicos para a produção do conhecimento e a intervenção social, sendo a pesquisa considerada princípio pedagógico; b) o currículo considerado como resultado de um processo de seleção e produção de saberes que acontece de forma consensual, uma concepção que apresenta influência das teorias críticas do currículo; c) organização curricular proposta em eixos tecnológicos, que deve considerar a matriz 
tecnológica, com métodos, técnicas e outros elementos das tecnologias relativas aos cursos; d) núcleo politécnico comum, que está relacionado aos fundamentos científicos, sociais, organizacionais, econômicos, políticos, culturais, ambientais, estéticos e éticos que alicerçam as tecnologias; e) conhecimentos e habilidades nas áreas de linguagem e códigos, ciências humanas, matemática e ciências da natureza, vinculados à educação básica, considerados essenciais para formação e desenvolvimento profissional do cidadão; f) trabalho como princípio educativo; e g) atualização permanente dos cursos e currículos. Outrossim, essa perspectiva de formação apresenta princípios como da interdisciplinaridade, da contextualização e da integração entre teorias e práticas no processo de ensino-aprendizagem (BRASIL, 2012a, 2012b).

A respeito da segunda perspectiva de formação, tem-se a indicação de conceitos e concepções que é contraditória em relação à concepção ampliada de formação, tais como: a) a justificativa das diretrizes voltada para formação centrada, exclusivamente em aspectos econômicos e para atender alterações legais; b) a possibilidade de estabelecer cursos que não sejam integrados, ou seja, oferta dos cursos de educação profissional de nível médio de forma articulada concomitante e subsequente; c) a indicação da integração entre educação geral e educação profissional que pode propiciar a justaposição de disciplinas; e d) o empreendedorismo como indicação de parte do currículo dos cursos de educação profissional (BRASIL, 2012a, 2012b).

É importante sublinhar que as contradições apresentadas se referem à concepção de educação profissional, o que pode reforçar a dualidade histórica existente nesta modalidade de ensino no Brasil.

\section{A recontextualização das políticas curriculares nos projetos pedagógicos}

No processo de recontextualização, no âmbito da Instituição Formadora, contexto secundário (BERNSTEIN, 1996), existe uma disposição de reproduzir as políticas públicas voltadas para a educação profissional. Sendo assim, o PDI indica que a Instituição Formadora deve balizar suas ações a partir de três perspectivas: a) ruptura com a dicotomia teoria e prática; b) flexibilidade curricular e mobilidade; e c) articulação entre ensino, pesquisa e extensão, o que apresenta aproximações com a proposta das DCNEP.

A respeito da educação profissional técnica de nível médio, o PDI apresenta reprodução, na íntegra, dos princípios norteadores estabelecidos na Resolução CNE/CEB n. 06/12, o que indica a intenção de reproduzi-los na proposição de seus cursos. Uma novidade é que é destinado um percentual da carga horária total dos cursos técnicos integrados, de 20\% na modalidade a distância. Trata-se de uma possibilidade que também foi estabelecida a partir da referida resolução.

No tocante ao currículo prescrito no âmbito do Campus Formador, foram analisados os PPCs (Projetos Pedagógicos de Cursos) dos cursos técnicos ofertados (Automação Industrial, Edificações, Eletrotécnica, Informática para Internet e Segurança do Trabalho). Os PPCs dos cursos apresentam os fundamentos filosóficos da prática educativa emancipatória e transformadora e a concepção de ser humano amplo, compreendido como ser histórico social que age sobre a natureza para satisfazer suas necessidades. 
Entretanto, os objetivos geral e específicos de curso tomam outra direção, focalizando o caráter técnico da formação e não abordando aspectos de uma formação ampliada, relacionados, por exemplo, com a formação para a cidadania, diferente do que acontece com o perfil profissional que contempla aspectos da formação técnica e da formação geral na indicação do que os trabalhadores devem realizar em seu futuro labor.

Os cursos técnicos integrados estão organizados em regime anual, com a matriz curricular elaborada por disciplinas e os cursos subsequentes são ofertados em regime semestral, com a matriz curricular organizada por disciplinas, em regime modular. A respeito da organização curricular, foi identifıcada a manutenção das disciplinas indicadas pelas Diretrizes Curriculares Nacionais do Ensino Médio (DCNEM) localizadas no núcleo comum, com uma disposição de reproduzir uma hierarquia tradicional dos componentes curriculares, o que se afasta de uma perspectiva de formação humana ampliada. Os conhecimentos de formação geral e de formação técnica permanecem separados pelos componentes curriculares de Núcleo Comum e os componentes curriculares do Núcleo Profissionalizante. No entanto, existem espaços considerados de integração de conhecimentos de formação geral e técnica, em ofertas de componentes curriculares que fazem parte do chamado Núcleo Diversificado.

\section{O processo de implantação das políticas curriculares na Instituição Formadora}

A respeito do processo de implantação das DCNEP na Instituição Formadora, observou-se que a gestão é desenvolvida pela Proen e a gestão em nível do Campus Formador. A Proen tem realizado alteração dos PPCs e das matrizes curriculares dos cursos técnicos; ações de formação continuada destinadas aos docentes e técnicosadministrativos; realização de trabalho piloto de reformulação curricular e diálogos entre representantes da Proen e os campi, denominados de Pró-Reitoria Itinerante.

No contexto do Campus Formador, as ações relacionadas à implantação das DCNEP são a elaboração dos PPCs em acordo com essas diretrizes curriculares; e reuniões pedagógicas que acontecem no início de cada semestre (planejamento pedagógico) e no decorrer do ano letivo. Nessas reuniões, são realizadas atividades, como diálogos entre os docentes, no formato de palestras e/ou debates sobre os temas que as atuais DCNEP apresentam. As ações realizadas pela Instituição Formadora e pelo Campus Formador para implementar as atuais políticas curriculares constituem-se momentos de formação continuada que apresentam formatos diferentes.

A avaliação dos gestores a respeito do processo de implantação das novas DCNEP foi positiva, considerando que o trabalho realizado pela gestão tem sido a contento. A respeito do impacto que as políticas curriculares apresentaram na organização do trabalho docente, gestores apresentaram posições distintas. 0 Diretor do Campus Formador compreende que a chegada das atuais DCNEP não representou uma novidade na organização do trabalho pedagógico devido à indicação de integração do ensino médio com a educação profissional, pois o Decreto n. 5.154/04 já realizara essa indicação: 
[...] antes das DCNEP serem aprovadas o ensino médio integrado veio por meio do Decreto $\mathrm{n}$. 5.154, que substituiu o Decreto n. 2.208, que na época separou o ensino médio da educação profissional. Então, esse novo decreto veio possibilitar a integração entre as várias formas de articulação do ensino médio com a educação profissional. Então, a partir do Decreto n. 5.154, foi possivel instituir novamente a integração do ensino médio com a educação profissional. (DIRETOR DO CAMPUS FORMADOR, 2004).

Assim, para o gestor, a chegada das DCNEP não representou um impacto na organização do trabalho docente, pois a grande alteração curricular já havia sido indicada no Decreto n. 5.154/04, que era a possibilidade da integração do ensino médio com o ensino profissional, em andamento na instituição. Já o Pró-Reitor de ensino considerou que as DCENP apresentaram caminhos para operacionalizar a integração curricular, o que possibilitou a resolução de problemas anteriores relacionados às questões operacionais:

As diretrizes reforçam, embora o decreto tenha avançado bem mais. Mas ela reforça, detalha, mostra caminhos de como fazer, metodologia, estipula a carga horária, por exemplo. Talvez se estivesse saído junto com o Decreto n. 5.154, orientando sobre as cargas horárias dos cursos. Nesse sentido, ela contribui para implementação dos cursos do ensino médio integrado, só que, mesmo depois dela, ainda existe um lapso de tempo que nós estamos demorando para entender essa concepção, alguns institutos estão mais na frente, outros ainda não. Tanto é que existem instituições com ensino médio de quatro anos, totalmente separado, apesar de ser chamado de ensino médio, e não tem integração nenhuma. (PRÓ-REITOR DE ENSINO, 2004).

A avaliação realizada pelos gestores a respeito da participação dos docentes, de forma geral, foi positiva, mas foi ressaltado que alguns professores apresentam resistências em aceitar mudanças, tais como alterações (diminuição) de carga horária, implantação da carga horária a distância e desenvolvimento do trabalho de integração com professores de outras disciplinas. Também foi considerado que os professores com mais tempo de serviço tendem a ser mais resistentes às mudanças curriculares.

Os gestores também consideram que a Instituição Formadora ainda não conseguiu realizar, de forma efetiva, a integração entre a educação técnica e a educação básica em seus cursos integrados e levantaram os seguintes fatores: a) formação inicial dos professores, que não abordam o tema da educação profissional e a integração curricular; b) a falta de formação continuada e de integração entre os professores e as disciplinas; e c) a falta de conhecimento dos professores sobre integração, que contribui para a não integração curricular dos cursos integrados e assim se tornando responsáveis pela não integração curricular.

\section{O trabalho prescrito}

Os professores que atuam no Campus Formador, ao desenvolver o seu trabalho, encontram um quadro normativo que contribuem para formar os aspectos prescritivos do trabalho, ou seja, o trabalho prescrito. 0 trabalho prescrito é formado, pelo menos, por três elementos: a) condições determinadas de trabalho; b) resultados antecipados; e 
c) objetivos encaminhados aos trabalhadores, que indicam o que deve ser realizado pelo trabalhador, ou seja, a tarefa a ser realizada (GUÉRIN et al., 2001).

No Campus Formador, aspectos como a identidade institucional e a estrutura administrativa da Instituição Formadora, a gestão escolar, a estrutura física, os materiais pedagógicos, o calendário acadêmico, entre outros aspectos, constituem-se elementos do trabalho prescrito e contribuem para conformar um quadro segundo o qual os professores desenvolvem sua atividade de trabalho.

A identidade institucional dos Institutos Federais - IF está fundamentada em três características principais, a saber: função social, organização didático-curricular e exercício profissional dos professores. Assim, os IF foram formados de modo descentralizado, com o objetivo de promover a interiorização de suas unidades de ensino (PEREIRA, s.d.) e apresentam um desenho didático-curricular a partir da transversalidade e da verticalização (PACHECO; PEREIRA; DOMINGOS SOBRINHO, 2010).

A estrutura administrativa é formada por uma administração central, localizada na Reitoria, que tem Pró-Reitorias responsáveis por áreas específicas na instituição. Já a gestão no Campus Formador fica sob a responsabilidade do diretor geral, juntamente com gerentes e coordenadores que formam uma equipe de gestores. Essa equipe pode ser constituída por professores e/ou técnicos-administrativos. A gestão escolar tem um caráter democrático com uma relação amistosa entre professores e equipe gestora do Campus.

0 exercício profissional dos docentes é desenvolvido com atribuições de atividades de ensino, pesquisa, extensão, bem como atividades de gestão e representação e o campus tem boa estrutura física, com salas, laboratórios, auditório, entre outros espaços. Os materiais pedagógicos disponíveis são variados, desde materiais esportivos até lousa digital. 0 calendário da Instituição Formadora é organizado por trimestre.

De um modo geral, os docentes que trabalham na Instituição Formadora tiveram ingresso por concurso público de provas e títulos, exercem o seu trabalho sob o regime de dedicação exclusiva para que possam desenvolver ensino, pesquisa e extensão. Sobre o fato de serem docentes na Instituição Formadora, os professores entrevistados fizeram uma avaliação bastante positiva, evocando, em muitos momentos, a sensação de realização por estarem trabalhando nessa instituição. Um professor, quando questionado acerca da avaliação que realizava da sua profissão, respondeu: "Positivo, muito positivo. Na minha carreira profissional eu me sinto realizado" (PROFESSOR DE SOCIOLOGIA). 0 aspecto laboral narrado é uma evidência interessante, visto que ressalta a positividade do trabalho docente realizado na Instituição Formadora.

Da análise documental cabe ainda considerar que legislações, no âmbito das políticas públicas, também apresentam elementos do trabalho prescrito aos professores. Um bom exemplo é a LDB, que, em seu artigo n.13, indica a incumbência dos professores em seu trabalho:

I. participar da elaboração da proposta pedagógica do estabelecimento de ensino;

II. elaborar e cumprir plano de trabalho, segundo a proposta pedagógica do estabelecimento de ensino;

III. zelar pela aprendizagem dos alunos; 
IV. estabelecer estratégias de recuperação para os alunos de menor rendimento;

V. ministrar os dias letivos e horas-aula estabelecidos, além de participar integralmente dos períodos dedicados ao planejamento, à avaliação e ao desenvolvimento profissional;

VI. colaborar com as atividades de articulação da escola com as famílias e a comunidade. (BRASIL, 1996, n.p).

É importante observar que a legislação, entre os instrumentos de prescrição curricular, estabelece aos professores ações que devem desempenhar no contexto de seu trabalho, o que contribui para estabelecer a tarefa a ser realizada pelos docentes. Mas vale destacar que nenhuma prescrição substitui o indispensável pleno domínio do referencial teórico e metodológico da ação docente, que, aliás, precisa a preceder. A pesquisa revelou muito bem isso.

\section{Os fatores que influenciam o trabalho docente}

De acordo com a investigação realizada, foi possível identificar diferentes aspectos que atravessam e, dessa forma, influenciam o trabalho docente dos professores participantes da pesquisa do Campus Formador, tais como: o encontro de histórias, a dimensão pessoal e o caráter socioeconômico do trabalho, a organização do trabalho pedagógico, os estudantes, o campo disciplinar e a área de atuação, a experiência profissional, as políticas educacionais e curriculares e os valores dos professores.

A Instituição Formadora, como outras instituições sociais, tem sua história, o seu significado social, assim como os professores carregam consigo sua história de vida, suas experiências profissionais e pessoais, que acabam atravessando a atividade de trabalho. No depoimento, a professora de matemática, ao expor sobre o seu trabalho, abordou essas questões:

Eu sou de uma cidadezinha bem pequena [...]. Então, toda a minha vida escolar foi em escolas públicas e eu venho de uma escola onde eu tive um professor de matemática praticamente todo ensino fundamental e médio. E esse professor de matemática não tinha formação de matemática. Então, eu sei muito bem qual é o impacto, veja bem, não estou falando mal do meu professor, eu estou falando que ele não era formado na área, ele não tinha esse conhecimento matemático necessário, totalmente, para dar aula para todo o ensino fundamental e ensino médio [...]. Perceba, a gente que se forma em uma universidade pública tem a formação preocupada com a parte prática, onde nós fazemos a diferença é em uma instituição pública. Porque é lá que você vai ter os alunos que não têm, financeiramente, condições de estar em uma escola particular, então, é lá que você faz a diferença enquanto professor; porque você dá possibilidade para os alunos terem um professor que tem domínio de conteúdo, que sabe o que ele está falando. (PROFESSORA DE MATEMÁTICA).

Percebe-se que, na entrevista, o reconhecimento do que a escola pública significa socialmente e a própria história de vida da professora a impulsionam a querer realizar um trabalho com o ensino de matemática no mínimo diferente do que ela vivenciou em sua formação na educação básica. 
Relacionados com a história do professor como protagonista da atividade de trabalho, estão sua dimensão pessoal e o caráter socioeconômico do trabalho. A dimensão pessoal refere-se às estratégias pessoais usadas pelos trabalhadores no seu labor. Fatores como idade, gênero, história e experiência de vida pessoal e profissional, entre outros, fazem parte dessa dimensão (GUÉRIN et al., 2001).

Sendo assim, trabalhar é deixar sua marca e realizar investimento pessoal. Desse modo, o professor simplesmente não apenas trabalha, mas ele engaja e investe em si mesmo (GUÉRIN et al., 2001, TARDIF; LESSARD, 2005). Por exemplo, foi identificado que a professora de Biologia se relaciona de forma bastante afetuosa e carinhosa com os estudantes, sendo uma característica específica dela. No entanto, essa característica parece ter sido ampliada com a chegada da maternidade da professora. Segundo ela, a forma de lidar com os estudantes ficou mais amorosa, mais humana:

Eu sempre fui amorosa com os meus alunos, muito humana, sempre tive uma paixão muito grande por eles. Eu tenho 21 anos de sala de aula e nunca tirei um aluno de sala de aula, eu não sei o que é gritar para um aluno calar a boca, primeiro que eu acho falta de respeito demais, então, por ter esse cuidado, esse carinho por eles. Depois que eu me tornei mãe aí que eu morro de paixão (risos) [...]. Então, eu me tornei mais amorosa ainda com esses alunos. (PROFESSORA BERTHA).

Esse aspecto também influencia a forma como a professora se relaciona com o seu trabalho como um todo. Observa-se aqui como uma relação afetiva em meio familiar (relação mãe-filho) parece potencializar a relação afetiva entre professora e estudantes. Embora esse não tenha sido o foco central da pesquisa, certamente é um assunto que merece aprofundamento e distinção.

Além do aspecto pessoal, o aspecto econômico é uma importante dimensão do trabalho. Segundo Guérin et al. (2001), o trabalho sofre influência da organização social e econômica em que está inserido, sendo resultado da inserção em uma organização social e econômica de produção. Desse modo, a instituição escolar não fica alheia a esse processo. A organização do trabalho, relações hierárquicas, o estatuto, o salário e a divisão das aulas em tempo são aspectos que sofrem influência mútua na materialização curricular.

Outro aspecto que influencia o desenvolvimento do trabalho refere-se à organização do trabalho pedagógico. A escola é uma instituição cuja organização e características organizacionais e sociais influenciam a própria organização e desenvolvimento do trabalho dos professores no contexto da aula (FREITAS, 2000; TARDIF; LESSARD, 2005; GIMENO SACRISTÁN, 2000). Nesse sentido, foi possível perceber a influência dessa organização de diferentes formas. Como exemplo, citam-se a organização do ano letivo (por trimestre), a estrutura física da escola, a gestão e a distribuição dos tempos curriculares, entre outros aspectos.

Entre os principais sujeitos elencados nas entrevistas que influenciam o trabalho docente dos interlocutores da pesquisa estão os estudantes. Isso porque um dos aspectos enfatizados pelos interlocutores foi que os conteúdos que são ensinados precisam ser ajustados aos interesses e necessidades dos estudantes. Esse ajuste refere-se à capacidade do alunado em realizar as atividades propostas e de compreender o ensino: 
Eu sempre, eu tento dividir o conteúdo de uma maneira que eles tenham a noção, por exemplo, não dava para eu trabalhar Bioquímica no primeiro ano, porque eles não estudaram ainda química orgânica. (INSTRUÇÃO AO SÓSIA: PROFESSORA DE BIOLOGIA).

A professora informou que procura organizar o conteúdo de forma que os estudantes consigam compreender o que está sendo tratado. No exemplo, ela cita a exclusão de um tema (bioquímica), porque os estudantes não apresentavam conhecimento sobre química orgânica. Observa-se que a organização da escola, dos componentes curriculares e a concepção que a professora tem do campo disciplinar também atravessam essa questão. Outros professores informaram que procuram selecionar conteúdos que estejam mais contextualizados com a vida dos estudantes, objetivando potencializar o aprendizado. Entretanto, essa postura docente merece reflexão, pois um aspecto é atender às demandas estudantis, outro é suprimir conteúdos curriculares por falta de pré-requisito. Na verdade, as lacunas de conteúdos nas passagens entre ciclos e tempos de aprendizagem ainda são grande desafio curricular a ser superado na organização do trabalho pedagógico, principalmente em tempos de reconhecimento do necessário e indispensável respeito às diversidades, em uma educação que se pretende inclusiva.

A influência do campo disciplinar é outro aspecto que as evidências da pesquisa revelaram, principalmente quando se refere aos professores que ministram componentes curriculares da formação técnica e da formação geral. Foi identificado que os professores que ministram as disciplinas de conteúdo técnico têm o mundo do trabalho como um importante valor no processo de ensino-aprendizagem. Já os professores das disciplinas do núcleo comum lançam o olhar mais para o cotidiano da vida dos estudantes e, em alguns casos, para as políticas de avaliação, principalmente referente ao Exame Nacional do Ensino Médio (ENEM), isso devido à influência dos estudantes. Outro aspecto refere-se aos materiais didáticos, uma vez que os professores de disciplinas do núcleo comum utilizam livros didáticos, textos. Já os professores das disciplinas técnicas, como não têm livros didáticos relacionados às suas disciplinas, utilizam livros técnicos da área profissional e, em muitos casos, de nível superior e apostilas, que são uma espécie de adaptação do conteúdo para o ensino médio.

Outro aspecto que influencia o trabalho docente, evidenciado na investigação, foi a experiência profissional. Essa constitui o que se pode denominar de saberes em patrimônio, ou seja, aqueles infiltrados nas situações laborais, que são dotados de historicidade (SCHWARTZ, 2003, 2010). Esses saberes são erigidos por meio da atividade de trabalho. $\mathrm{Na}$ experiência de trabalho de integração de conhecimentos desenvolvida pelo professor da área de Edificações, ele informou que vem realizando essa ação a partir da experiência profissional na tentativa de chamar a atenção dos estudantes. Ao explicar como começou a integralizar conhecimentos, ele respondeu:

E eu testei em sala e deu muito certo. Porque eu percebo que os alunos têm aulas que eu falo até sobre acústica da física, eu falo sobre questão térmica, dilatação. Então, percebo que isso chama a atenção deles porque eles vão lembrar do que estudaram: - nossa eu vi isso lá na matéria do professor de física, eu vi isso na matéria de química, eu vi isso em biologia. Por exemplo, quando 
estou falando em estruturas e madeiras eu vou citar os tipos de plantas existentes, quais nós utilizamos nas estruturas, isso chama a atenção deles. (PROFESSOR DE EDIFICAÇÕES).

Segundo o professor, quando não procede de tal forma, os estudantes ficam dispersos. Então, a partir da apropriação desses saberes do patrimônio, que foram erigidos no contexto da experiência profissional, ele desenvolve essa característica.

Na presente pesquisa, também foram identificados valores dos interlocutores que estão em jogo no desenvolvimento do trabalho. Esses valores são: a valorização do trabalho pedagógico entre os professores e estudantes; a participação e a compreensão dos estudantes em relação ao conteúdo que estava sendo ensinado; contextualização dos conteúdos, procurando aproximar-se da realidade dos estudantes; valorização da área de atuação profissional; a boa relação com os estudantes, observada na utilização de uma linguagem que se aproxima deles e com uma relação pautada no respeito e permeada de afeto e descontração; a atenção, a participação e a compreensão dos estudantes durante o processo de ensino, que foram expressos na preocupação com o ambiente de aprendizagem e as perguntas encaminhadas para eles permanecerem atentos à aula. Os professores articulam esses valores relacionados com os estudantes, com a área disciplinar, com as técnicas de ensino.

Porém, foi identificado que os professores desconhecem as diretrizes das atuais políticas curriculares da educação profissional técnica de nível médio. Assim, essas diretrizes curriculares influenciam, de forma mais efetiva, a prática dos professores por meio da organização do trabalho pedagógico geral da escola e do currículo prescrito dos cursos técnicos integrados, relacionados aos aspectos operacionais do currículo.

\section{Considerações finais}

A partir das análises, foi possivel identificar que o processo de implantação das DCNEP no Campus Formador vem sendo realizado a partir de ações propostas pela equipe gestora da Reitoria e do Campus Formador, o que demonstra preocupação com o processo de implantação dessas diretrizes.

Entretanto, as ações propostas têm apresentado pouco efeito na compreensão e nas práticas dos professores entrevistados do Campus Formador com relação às orientações das DCNEP, visto que, no trabalho dos professores, outros elementos influenciam sua ação e os gestores parecem desconhecer ou desconsiderar esses elementos.

Nesse sentido, o maior esforço empreendido nessas ações baliza-se, em grande medida, em resolver problemas pragmáticos relacionados à operacionalização do currículo prescrito a partir dessas políticas, como a diminuição da alta carga horária dos cursos integrados. Também, as ações empreendidas pela gestão não foram elaboradas com a participação dos professores. Por fim, recomenda-se que outros estudos sejam realizados a respeito da implantação de políticas curriculares e o trabalho docente. 


\section{Referências}

BERNSTEIN, Basil. A estruturação do discurso pedagógico: classe, código e controle. Petrópolis: Vozes, 1996.

BRASIL. Decreto $n^{\circ}$ 5.154, de 23 de julho de 2004. Regulamenta $0 \S 2^{\circ}$ do art. 36 e os arts. 39 a 41 da Lei $n^{0}$ 9.394, de 20 de dezembro de 1996, que estabelece as diretrizes e bases da educação nacional, e dá outras providências. Brasília, DF: [s. n.], 2004. Disponível em: http://www.planalto.gov.br/ccivil_03/_ ato2004-2006/2004/decreto/d5154.htm. Acesso em: 07 dez. 2016.

BRASIL. Lei n. 9394, de 20 de dezembro de 1996. Diretrizes e Bases da Educação Nacional. Brasília, DF: MEC, 1996. Disponível em: http://portal.mec.gov.br/secad/arquivos/pdf/ldb.pdf. Acesso em: 7 jul. 2016.

BRASIL. Lei n. 13.415, de 16 de fevereiro de 2017. Brasília, DF: Casa Civil, 2017. Disponível em: http:// www.planalto.gov.br/ccivil_03/_ato2015-2018/2017/Lei/L13415.htm. Acesso em: 22 fev. 2017.

BRASIL. CNE. CEB. Parecer n.11, de 9 de maio de 2012. Diretrizes curriculares nacionais para a educação profissional técnica de nível médio. Brasília, DF: CNE, 2012a. Disponível em: http://portal.mec.gov.br/ index.php?option=com_docman\&view=download\&alias=10804-pceb011-12-pdf\&ltemid=30192. Acesso em: 7 jul. 2016.

BRASIL. CNE. CEB. Resolução n. 4. Institui as diretrizes curriculares nacionais para educação profissional de nível técnico. Brasília, 8 de dezembro de 1999. Brasília, DF: CNE, 1999. Disponível em: http://portal. mec.gov.br/index.php?option=com_content\&id=12992. Acesso em: 7 jul. 2016.

BRASIL. CNE. CEB. Resolução n. 6. Define as diretrizes curriculares nacionais para a educação profissional técnica de nível médio. Brasília, 20 de setembro de 2012. Brasília, DF: CNE, 2012b. Disponível em: http:// portal.mec.gov.br/index.php?option=com_content\&id=12992. Acesso em: 7 jul. 2016.

CANDAU, Vera Maria. Reformas educacionais hoje na América Latina. In: MOREIRA, Antônio Flávio Barbosa (org.). Currículo: políticas e práticas. 4. ed. Campinas: Papirus, 2001. p. 29-42.

FERRETTI, Celso João. Formação profissional e reforma do ensino técnico: anos 90. Educação \& Sociedade, Campinas, v. 18, n. 59, p. 225-269, 1997.

FREITAS, Luiz Carlos de. Crítica da organização do trabalho pedagógico e da didática. 3. ed. Campinas: Papirus, 2000.

FRIGOTTO, Gaudêncio; CIAVATTA, Maria; RAMOS, Marise. A gênese do Decreto n. 5.154/2004: um debate no contexto controverso da democracia restrita. In: FRIGOTTO, Gaudêncio; CIAVATTA, Maria; RAMOS, Marise (org.). Ensino médio integrado: concepções e contradições. 3. ed. São Paulo: Cortez, 2012. p. 21-56.

GIMENO SACRISTÁN, José. O currículo: os conteúdos do ensino ou uma análise da prática? In: GIMENO SACRISTÁN, José; PÉREZ GÓMEZ, Angel Ignacio. Compreender e transformar o ensino. 4. ed. Porto Alegre: Artmed, 1998. p. 119-148. 
GIMENO SACRISTÁN, José. 0 currículo: uma reflexão sobre a prática. 3. ed. Porto Alegre: Artmed, 2000.

GIMENO SACRISTÁN, José. O currículo em ação: os resultados como legitimação do currículo. In: GIMENO SACRISTÁN, José (org.). Saberes e incertezas sobre o currículo. Porto Alegre: Penso, 2013b. p. 262-280.

GIMENO SACRISTÁN, José. 0 que significa o currículo? In: GIMENO SACRISTÁN, José (org.). Saberes e incertezas sobre o currículo. Porto Alegre: Penso, 2013a. p. 16-35.

GUÉRIN, François et al. Compreender o trabalho para transformá-lo: a prática da ergonomia. São Paulo: Edgard Blücher: Fundação Vanzolini, 2001.

KUENZER, Acácia Zeneida. A questão do ensino médio no Brasil: a difícil superação da dualidade estrutural. In: MACHAD0, Lucília Regina de Souza et al. Trabalho e educação. 2.ed. Campinas: Papirus, 1994. p.113-128. (Coletânea CBE).

KUENZER, Acácia Zeneida. Reforma da educação profissional ou ajuste ao regime de acumulação flexível? Trabalho, Educação e Saúde, Rio de Janeiro, v. 5 n. 3, p. 491-508, 2008.

MAINARDES, Jefferson; STREMEL, Silvana. A teoria de Basil Bernstein e algumas de suas contribuições para as pesquisas sobre políticas educacionais e curriculares. Revista Teias, Rio de Janeiro, v.11, n. 22, p. 31-54, 2010.

PACHECO, Eliezer; PEREIRA, Luiz Augusto Caldas; DOMINGOS SOBRINHO, Moisés. Institutos federais de educação, ciência e tecnologia: limites e possibilidades. Linhas Críticas, Brasília, DF, v. 16, n. 30, p. $71-88,2010$.

PEREIRA, Luiz Augusto Caldas. A expansão da Rede Federal de Educação Profissional e Tecnológica. [S. I.: s. n.: s.d.]. Disponível em: http://portal.mec.gov.br/setec/arquivos/pdf2/artigos_caldas.pdf. Acesso em: 8 jul. 2015.

SAVIANI, Dermeval. A nova lei da educação: trajetórias, limites e perspectivas. 5. ed. Campinas: Autores Associados, 1999.

SAVIANI, Dermeval. Política educacional brasileira: limites e perspectivas. Revista de Educação PUCCampinas, Campinas, n. 4, p.7-16, 2008.

SCHWARTZ, Yves. A abordagem do trabalho reconfigura nossa relação com os saberes acadêmicos: as antecipações do trabalho. In: SOUZA-E-SILVA, Maria Cecília Pérez; FAÏTA, Daniel (org.). Linguagem e trabalho: construção de objetos de análises no Brasil e na França. São Paulo: Cortez, 2002. p. 109-126.

SCHWARTZ, Yves. A experiência é formadora? Educação \& Realidade, Porto Alegre, v. 35, n.1, p. 35-48, 2010.

SCHWARTZ, Yves. Circulações, dramáticas, eficácias da atividade industriosa. Trabalho, Educação e Saúde, Rio de Janeiro, v. 2, n. 1, p. 33-55, 2004. 
SCHWARTZ, Yves. Conceituando o trabalho, o visível e o invisível. Trabalho, Educação e Saúde, Rio de Janeiro, v. 9, supl. 1, p. 19-45, 2011.

SCHWARTZ, Yves. Entrevista: Yves Schwart. Trabalho, Educação e Saúde, Rio de Janeiro, v. 4 n. 2, p. 457-466, 2006.

SCHWARTZ, Yves. Trabalho e saber. Trabalho \& Educação, Belo Horizonte, v. 12, n. 1, p.21-34, 2003.

SCHWARTZ, Yves. Trabalho e valor. Tempo Social, São Paulo, v. 8, n. 2, p. 147-158, 1996.

SCHWARTZ, Yves. Reflexão em torno de um exemplo de trabalho operário. In: SCHWARTZ, Yves; DURRIVE, Louis. Trabalho e ergologia: conversas sobre a atividade humana. Niterói: Universidade Federal Fluminense, 2007. p. 37-46.

SCHWARTZ, Yves; DUC, Marcelle; DURRIVE, Louis. Trabalho e ergologia. In: SCHWARTZ, Yves; DURRIVE, Louis (org.). Trabalho e ergologia: conversas sobre a atividade humana. Niterói: Universidade Federal Fluminense, 2007. p. 25-36.

SILVA, Marta Leandro; MARQUES, Waldemar. As políticas da educação profissional e tecnológica no Brasil: rediscutindo a institucionalidade do ensino técnico. Ensino em Revista, Uberlândia, v. 14, n. 1, p. 91-105, 2007.

TARDIF, Maurice; LESSARD, Claude. 0 trabalho docente: elementos para uma teoria da docência como profissional de interações humanas. Petrópolis: Vozes, 2005.

Recebido em: 13.04.2019

Aprovado em: 18.02.2020

Néri Emílio Soares Júnior é professor do Instituto Federal de Ciência, Educação e Tecnologia de Goiás (IFG), mestre e doutor em educação pela Universidade de Brasília (UnB). Integrante do grupo de pesquisa: Currículo: Concepções Teóricas e Práticas Educativas.

Lívia Freitas Fonseca Borges é professora associada da Faculdade de Educação da Universidade de Brasília (UnB). Líder do grupo de pesquisa: Currículo: Concepções Teóricas e Práticas Educativas. 